\title{
Monitoring and Controlling of Soft Foundation Settlement Deformation in Expressway Construction
}

\author{
Li Yong \\ Road \& Bridge North China engineering CO.,LTD. China Beijing 101100
}

Keywords: expressway; soft foundation settlement deformation; monitoring; control

\begin{abstract}
Expressway plays a vital role in traffic construction. China attaches great importance to the construction of expressways. In recent years, the number of expressway construction projects has increased. In expressway construction, soft foundation settlement deformation will seriously affect the stability and carrying capacity of expressway subgrade. Therefore, it is necessary to strengthen the monitoring and control of soft foundation settlement deformation of expressway construction. This paper briefly introduces the soft foundation settlement deformation monitored project, analyzes the deployment and data analysis of the soft foundation settlement deformation monitoring instrument, and explores the soft foundation settlement deformation control standard and information management, in order to provide reference for expressway construction.
\end{abstract}

\section{Introduction}

In order to effectively guarantee the construction quality of expressway construction, we must control the foundation settlement strictly, especially to strengthen the monitoring and control of soft foundation settlement deformation, effectively ensuring the expressway subgrade has good stability and strong carrying capacity. During the construction of the expressway, relevant technical personnel should strengthen the preparation work, set the monitoring points reasonably along the expressway, and record and accurately count the data in real time. At the same time, it is necessary to focus on the dynamic changes of foundation loads and scientific analysis and reasonable prediction of soft foundation settlement.

\section{Erview of soft foundation settlement deformation monitoring project}

During the construction of the expressway, monitoring the subgrade should thoroughly investigate the specific construction quality requirements of the expressway project and clarify the monitoring data. In general, soft foundation settlement deformation monitoring projects cover deformation observations and load and strength observations. There are two types of deformation observations, one is settlement observation and the other is horizontal displacement observation of soil. Load observations include compression changes that the subgrade exhibits when subjected to different loads. The strength test focuses on the contents of the single pile load and tests the crack. For surveying and mapping technicians, deformation observation is the main monitoring project. For settlement observation, the settlement observation target is usually pre-arranged, and then the second level observation is carried out by means of SI level meter. Based on the periodic observation, the settlement-time curve is drawn, and the post-construction settlement is scientifically analyzed. And reasonable prediction; for the horizontal displacement observation of the soil, usually by means of the inclinometer, after each measurement is completed, the two curves should be arranged, one is the horizontal displacement with depth curve, and the other is the horizontal displacement with time curve [1].

\section{The soft foundation settlement deformation monitoring instrument layout and data analysis}

Before implementing the soft foundation settlement deformation monitoring, it is necessary to scientifically formulate detailed and specific monitoring plans, then make reasonable selection of 
the testing instruments, and place the testing instruments at the preset monitoring points, record the monitoring data, and combine the construction process. The dynamic change data is tracked and recorded, and then the recorded data is analyzed by the hyperbolic method theory [2].

\subsection{Arrange the instrument}

To implement soft foundation settlement deformation monitoring, first of all, the relevant instruments should be arranged. First, the settling plate is to be laid. During the expressway construction process, the actual deployment density of the settlement monitoring points will have an important impact on the soft foundation settlement deformation monitoring. It is necessary to thoroughly investigate the corresponding geographical environment conditions of expressway construction and determine the actual layout density of the monitoring points. For example, expressway construction in the mountainous areas of the south, the geographical environment conditions are complex and variable, therefore, the use of higher monitoring points to set the density. For the northern plains, the terrain is flat and has a relatively simple soil quality. For this, it is not necessary to use a higher monitoring point to lay the density. In addition, weather changes can also affect the frequency of observations. If the weather conditions are stable, it will need to be monitored about three times a month. If the weather changes greatly in a short period of time, the monitoring frequency should be increased. Under various weather conditions, the deformation of soft foundation settlement can be accurately determined. To observe the horizontal displacement of the soil, the inclinometer should be well laid on the corresponding slope at both sides of the embankment. When embedding the inclined tube, it should be noted that the guiding groove is consistent with the measured displacement direction [3].

Pay attention to the details in the process of arranging the instrument. To strengthen the effective protection of the instrument, the fence or the more conspicuous sign should be placed around the monitoring instrument to avoid damage to the monitoring instrument caused by unrelated personnel.

At the same time, it is necessary not only to avoid the collision of the inclinometer, but also to seal the nozzle after each use, to prevent the tube from the falling of a foreign body so as to cause the obstruction of the inclinometer to be scrapped. If the monitoring point along the embankment is damaged, it needs to be reset and retested in time, and a new observation cycle and analysis cycle should be constructed. If the roadbed is obviously deformed, effective measures should be taken to control it in time to achieve effective reinforcement. It is necessary to use the data obtained from monitoring and sorting as a reference, scientifically change the roadbed structure and concrete composition, and get control of soft foundation settlement deformation according to the data.

\subsection{Analysis of the settlement data}

The settlement data should be analyzed to ensure that it is well comparable. Therefore, the observation time needs to be properly extended and is usually controlled at about five or six months, and the monthly settlement is calculated. For example, in July, the settlement of aexpressway section was $2.00 \mathrm{~mm} / \mathrm{month}$, the settlement in August was $1.78 \mathrm{~mm} / \mathrm{month}$, and the settlement in September was $1 \mathrm{~mm} / \mathrm{month}$. Comparing the data during this period, it can be seen that the settlement of the roadbed of the expressway section is significantly lowered, and it can be judged whether the settlement of the roadbed remains within the controllable range. According to the data analysis, it is necessary to strengthen the observation intensity and improve the observation accuracy for the expressway sections where the roadbed settlement are more serious. It is necessary not only to compare the corresponding data of the settlement before and after, but also to obtain the overall data, that is, the cumulative amount of settlement for the whole month or the cumulative accumulation of the monitored road sections within five months. According to the scientific analysis of the sedimentation accumulation, the quality of the roadbed is judged to ensure that the settlement remains within the normal range. For example, the observation instrument shows that there are as many as 18 observation points in the settlement of a expressway section in the range of $1 \mathrm{~mm}$ to $8 \mathrm{~mm}$, and there are 10 observation points in the settlement of $8 \mathrm{~mm}$ to $20 \mathrm{~mm}$. The analysis of the above data shows that the monthly cumulative amount of the expressway section is kept below $25 \mathrm{~mm}$, from which we can judge that the subgrade settlement of the expressway section is normal. 


\section{The control standard of soft foundation settlement deformation and information management}

In the construction of expressways, to fill the embankment, the settlement monitoring and stability monitoring should be implemented. The filling rate should be strictly controlled to avoid damage caused by excessive loading when the corresponding limit of the embankment is approached or reached. In the process of embankment filling, the monitoring frequency should be controlled as follows: during the construction period, each time one layer of filling is completed, an observation should be carried out; if the construction is stopped, an observation is required every three days; during the preloading period, observations are carried out every three days every month, and observations are carried out every seven days from the second month to the third month. In the fourth month, observations are carried out every half month until the pavement is paved.

\subsection{The control standard of soft base deformation}

In order to ensure the stability of the roadbed, the following criteria should be adopted to control the soft foundation deformation: the ground subsidence rate at the centerline of the embankment should be kept within $1.0 \mathrm{~cm}$ per day and night; the horizontal displacement of the slope foot should be kept within $0.5 \mathrm{~cm}$ per day and night. It is necessary to combine the development trend of vertical settlement and the development trend of horizontal displacement to comprehensively analyze the observation results. The filling rate should be controlled mainly by horizontal displacement. If the embankment reaches the design height, the settlement of the roadbed will gradually be stabilized after a certain period of preloading. Roadbed stability means that the current roadbed settlement rate and the prediction of post-construction settlement can achieve good satisfaction with relevant specifications. When the roadbed filling is completed, if the measured sedimentation rate is less than $5 \mathrm{~mm} / \mathrm{month}$ for two consecutive months after pre-pressing, the roadbed can be determined to be stable.

\subsection{Informational construction management}

The monitoring of soft foundation settlement deformation is to guide the construction of expressway by means of monitoring results, and provide relevant basis to optimize the design. Therefore, it is necessary to analyze and sort the soft foundation settlement deformation data, judge the safety and stability of the roadbed, and provide the results to the construction unit in time, and urge the construction unit to improve the construction method at any time to implement the informational construction management.

\section{Conclusion}

To sum up, in order to guarantee the construction quality of expressways, it is necessary to strengthen the monitoring of soft foundation settlement deformation, make sure that the expressway roadbed is equipped with good stability and strong bearing capacity. To implement soft foundation settlement deformation monitoring, it is necessary to rationally arrange the instruments, analyze the settlement data scientifically, follow the soft foundation deformation control standard, and implement informational management for roadbed construction.

\section{References}

[1] GuoLinyan. Preliminary Study on Monitoring and Control of Settlement Deformation of Expressway Soft Foundation [J]. Research of urban construction theory: e-edition, 2014(21).

[2] Li Qingzhen. Case Analysis of Deformation Monitoring of Soft Foundation Section of Pipeline Underpass [J]. Journal of Guangdong Vocational College of Communications, 2017, 16(2):5-8.

[3] Liu Guixia. Technology of expressway soft foundation embankment settlement observation [C]. // China Expressway Technology Innovation Forum. 2013. 
[4] Zhu Miaomiao, Xiang Xiqiong, Zhang Jinghua. Deformation Observation and Construction Control of Soft Soil Roadbed of Guihui Expressway [J]. Science and Technology of Western China, 2014(8):27-29.

[5] Wu Xianjin. Case Analysis on Monitoring of Settlement Deformation of Soft Foundation in Rural Roads [J]. JiangXi Materials, 2015(17):180-180. 